\title{
Carbon Leakage in Aviation Policy
}

\section{Lynnette Draya* and Khan Doymea}

aAir Transportation Systems Lab, UCL Energy Institute, 14 Upper Woburn Place, London, UK, WCIH ONN

*Email: 1.dray@ucl.ac.uk; Phone: +44 (0)7886 678564; ORCiD 0000-0003-3331-1246

\section{Acknowledgements}

This work is based on a study funded by the UK Department for Transport (contract reference: CCZZ18A11). All modelling, conclusions and opinions expressed are the authors' own. The authors are grateful to David Hart, Peter Morrell, Andreas Schäfer and Roger Gardner for providing data and insights into airline behaviour, and for reviewing the study outputs. 


\section{Carbon Leakage in Aviation Policy}

The inherently global, connected nature of aviation means that carbon leakage from aviation policy does not necessarily behave similarly to leakage from other sectors. We model carbon leakage from a range of aviation policy test cases applied to a specific country (the United Kingdom), motivated by a desire to reduce aviation $\mathrm{CO}_{2}$ faster than achievable by currently-planned global mitigation efforts in pursuit of a year-2050 net zero $\mathrm{CO}_{2}$ target. We find that there are two main components to leakage: one related to passenger behaviour, which tends to result in emissions reductions outside the policy area (negative leakage), and one related to airline behaviour, which tends to result in emissions increases outside the policy area (positive leakage). The overall leakage impact of a policy, and whether it is positive or negative, depends on the balance of these two components and the geographic scope used, and varies for different policy types. In our simulations, carbon pricing-type policies were associated with leakage of between +50 and $-150 \%$ depending on what is assumed about scope and the values of uncertain parameters. Mandatory biofuel use was associated with positive leakage of around 0-40\%, and changes in airport landing costs to promote more fuel-efficient aircraft were associated with positive leakage of 50$150 \%$.

- Carbon leakage in aviation policy arises from airline responses (typically positive leakage) and passenger responses (typically negative leakage).

- Depending on the geographical scope, policy type and values for uncertain parameters, leakage may be between around -150 to $+150 \%$.

- Of the policies investigated in this study, leakage was typically most negative for carbon pricing and most positive for environmental landing charges.

- Absolute values of leakage are smallest where policies are considered on the basis of all arriving and departing flights.

Keywords: aviation; carbon leakage; carbon pricing; biofuel 


\section{Introduction}

Carbon leakage occurs when a policy applied in one region of the world produces a change in $\mathrm{CO}_{2}$ outside that region (e.g. Intergovernmental Panel on Climate Change [IPCC], 2007). Normally, this change is an increase. This primarily results from cost differentials for companies operating within and outside the policy area. For example, companies outside the policy area may increase their global market share, or fuel use reductions within the policy area may lead to a global decrease in fuel prices, increasing use elsewhere (e.g. Reinaud, 2008; Burniaux and Oliviera-Martins, 2000). Typically, literature estimates of carbon leakage across all sectors vary from 2-25\%, depending on the policy examined and input assumptions (e.g. Kuik \& Hofkes, 2010; Di Maria \& van der Werf, 2008), although leakage for individual sectors may be higher. Some mechanisms can lead to negative leakage, i.e. $\mathrm{CO}_{2}$ reductions outside the policy area. For example, policy costs could drive investment in mitigation technology which is then used globally (Porter \& van der Linde, 1995).

Due in part to the difficulty of allocating emissions to different countries, bunker fuels from international aviation are excluded from the Kyoto Protocol, the Paris Agreement, and from national emissions totals under the UNFCCC. International efforts to mitigate aviation $\mathrm{CO}_{2}$ have focussed primarily on its inclusion in the EU Emissions Trading Scheme (ETS) and ICAO's global Carbon Offsetting and Reduction Scheme for International Aviation (CORSIA) scheme (Martinez Romera, 2016). CORSIA, which aims to achieve carbon-neutral growth for international aviation post-2020 by requiring the purchase of emissions offsets from other sectors, has been criticised for its relatively low level of ambition and the potential for double-counting in emissions reductions (Larsson et al, 2019). This may increase the likelihood of individual states or industry 
taking unilateral action (Martinez Romera, 2016). In particular, the UK applies distance-based passenger charges (Larsson et al., 2019) and is currently examining strategies to reach net zero emissions in 2050 with international aviation included (CCC, 2019). This implies much larger reductions in emissions than are planned under CORSIA, requiring additional UK-specific aviation policy and a corresponding risk of carbon leakage.

Most analyses of leakage concentrate on industrial sectors such as manufacturing and energy generation. The aviation sector, however, may behave differently. This is because of its global nature, with most flights producing emissions that can be attributed to multiple countries, the fact that passengers can choose which route to take, and the relative difficulty in reducing $\mathrm{CO}_{2}$ emissions from aviation (e.g. Dray et al., 2018). There are few analyses of aviation carbon leakage. Most focus on the 2012 addition of aviation to the EU ETS and are not peer-reviewed, have a primary focus that is not leakage, and/or consider impacts only on a case-study basis (e.g. Faber and Brinke, 2011; Ernst \& Young and York Aviation, 2008; CE Delft, 2005). None provide system-wide estimates of leakage.

The response of global aviation to policy depends on a series of potentially complex interactions between the decisions of airlines, passengers, and other stakeholders (e.g. Dray et al., 2018). In most cases, airlines will incur extra costs from the imposition of a policy. They will then decide whether to change their operations or fleet to try and reduce costs, pass costs onto ticket price, or accept reduced profit margins. Passengers faced with increased ticket prices will choose whether to continue with or change their journey, or not fly. This is complicated by the case where a policy 
applies only in one region, with only some of an airline's flights within scope. In this case, airline options include switching fleet between policy and non-policy routes, tankering to avoid taking on fuel at policy-affected airports, or selling older aircraft and buying newer ones. Passengers can choose to change routing to avoid or reduce impacts, or to not fly. Over the longer term, airlines and airline groups will also make decisions about where to invest and which routes to develop, which may be influenced by policy.

In this paper, we apply a network-based analysis of carbon leakage for the case of aviation emissions policy applied to a single country (the United Kingdom). Using models for passenger and airline behaviour from a systems model of global aviation (Dray et al., 2019), we assess the likely magnitude of leakage impacts and how sensitive outcomes are to different assumptions about key uncertain variables.

\section{Modelling framework}

To assess carbon leakage from policies applied in a single country, we use modified versions of components from the open-source global aviation systems model AIM (e.g. Dray et al. 2019). AIM models interactions between passenger demand, airline costs and behaviour, airport capacity, fleets, technology availability and policy. In this study, we apply hypothetical policies to the year-2015 system. First, we model year-2015 passenger demand, itinerary choice, fleets and emissions by route and airline type. Then we assess how different policies change airline costs, and how airlines and passengers may respond. To do this, we adjust models and data from AIM for city-pair demand, itinerary choice, airline fleets, costs and emissions. 


\section{City-pair demand}

AIM models demand for air travel on a city-pair basis (for example, total demand London-Sydney via any route), using a set of 878 global cities. In this study, we assess the impact of changing UK-specific aviation policy. We limit the scope to 20,000 citypairs for which the origin or destination city is in the UK, or for which one of the top nine itineraries offered in 2015 by passenger numbers routes through the UK. City-pair demand in 2015 is obtained from an AIM base year run using model fits to the Sabre (2017) database of global passenger numbers, schedules, routing and fares. A full description of the model and 2015 base year validation is given in Dray et al. (2019).

If a policy is applied, demand is likely to change as ticket prices change and passengers choose whether or not to fly. We capture this impact using a price elasticity of demand, i.e.

$$
D_{i j, \text { policy }}=D_{i j, \text { no policy }}\left(\bar{P}_{i j, \text { policy }} / \bar{P}_{i j, \text { no policy }}\right)^{\alpha},
$$

where $D_{i j}$ is the demand between cities $i$ and $j$ over all routes, $\bar{P}_{i j}$ is the average fare between $i$ and $j$ across all routes, and $\alpha$ is the price elasticity. The value of price elasticity for aviation is uncertain, and depends on passenger type, geographic scope and what kinds of substitution are considered (e.g. IATA, 2007; Brons et al., 2002; Oum et al., 1992). Because the exact value of elasticity has a significant impact on outcomes, we treat it as an uncertain variable and assess outcomes over a range of values. Commonly-used literature values for price elasticity range from around -1.5 to around -0.2 (e.g. Brons et al. 2002). Since we model itinerary choice separately, values on the smaller end of this range are more appropriate. We assess the impact of values in the range -0.2 to -0.8 , which is the range used for the UK in DfT (2017). 


\section{Itinerary choice}

Passengers between a given pair of cities usually have multiple route and airport choice options. For example, passengers between London and Sydney could choose to fly from London Heathrow Airport, through Dubai International Airport, to Sydney International Airport. To model this, we use a multinomial logit itinerary choice model estimated from Sabre (2017) data. The number of passengers $D_{i j k}$ between cities $i$ and $j$ on itinerary $k$ is modelled as

$$
D_{i j k}=\frac{D_{i j} e^{V_{i j k}}}{\sum_{k} e^{V_{i j k}}}
$$

where the deterministic part of the utility, $V_{i j k}$, for an itinerary $k$ travelling between airport $m$ in $i$ and airport $n$ in $j$, is:

$$
\begin{aligned}
& \quad V_{i j k}=\gamma_{0}+\gamma_{1} f_{i j k}+\gamma_{2} t_{i j k}+\gamma_{3} \ln f r e q_{i j k}+\gamma_{4} N l e g s_{i j k}+\gamma_{5} N_{m, y-1}+ \\
& \gamma_{6} N_{n, y-1}
\end{aligned}
$$

and $f_{i j k}$ is the itinerary fare, $t_{i j k}$ is the total itinerary travel time, freqijk is the itinerary frequency, Nlegsijk is the number of flight legs in the itinerary, $N_{m, y-1}$ is the total number of non-transfer scheduled passengers using airport $m$ in the previous year, and the parameters $\gamma$ are estimated. Itinerary and airport-level passenger numbers and fares are derived from Sabre (2017) passenger data. Itinerary frequency is defined as the minimum yearly flight frequency across all flight legs; this and itinerary journey time are derived from Sabre (2017) schedule data. Parameters and more information on model estimation are given in the supplemental information to this paper.

Applying this model to city-pair passenger demand allows demand by itinerary and airport-airport flight segment to be calculated. 


\section{Flights and $\mathrm{CO}_{2}$ emissions}

As in Dray et al. (2017), we divide the global aircraft fleet into nine size classes. We assume that policy-related costs will not substantially change the size distribution of aircraft operating on a given route (e.g. Givoni \& Rietveld, 2009), and that year-2015 load factors will be maintained. In this case, flight frequencies per route by size class scale with passenger numbers. Assuming typical aircraft utilisation by size class (FlightGlobal, 2016) and typical aircraft size distribution per route (Sabre, 2017), the fleet needed to carry out this schedule for UK and non-UK operators can be estimated. Additionally, using data from CAA (2017b), we add an extra $7 \%$ to flight totals per domestic segment and $14 \%$ to flight totals per international segment to account for nonscheduled flights.

$\mathrm{CO}_{2}$ emissions are modelled as in Dray et al. $(2018,2019)$. We use a model fit to the output of the PIANO-X performance model (Lissys, 2017) to calculate fuel use with payload and distance flown for a reference aircraft per size class, assuming $95 \mathrm{~kg}$ for a passenger plus luggage and typical belly freight load factors (ICAO, 2014). We assume a historical $1-1.2 \%$ per year average decrease in new aircraft model fuel use (e.g. Lee et al., 2001), and a $0.2 \%$ per year increase in fuel use per year of aircraft age (e.g. Morrell \& Dray, 2009). Existing fleet age distributions are derived from FlightGlobal (2016) and are shown in Figure 1. These distributions are primarily a function of historical fleet growth. Because UK airlines largely cater to established, slow-growing demand, their fleets are relatively old compared to global fleets.

\section{Airline costs}

We model airline costs by type as in Al Zayat et al. (2017). We assume policies may directly change airline fuel, carbon or landing costs. Additionally, changes in fleet or 
fleet assignment in response to policy may change airline finance and maintenance costs. A baseline fuel price of $\$ 0.63 / \mathrm{kg}$ (year 2015 US dollars) is assumed, along with an EU ETS carbon price of $\$ 7.9 / \mathrm{tCO}_{2}$ (DfT, 2017). Policy increases in fuel or carbon price are assumed additional to these values. We do not model the influence of changes in fuel demand on fuel prices (either within the aviation sector or more widely).

Although such changes may be a further source of leakage, they are highly uncertain and interact in a complex manner with other emissions mitigation efforts across sectors (e.g. Burniaux \& Oliveira Martins, 2000; Rosendahl \& Strand, 2011). For policy cases using biofuel, we assume a hypothetical biofuel price of $\$ 1.2 / \mathrm{kg}$ (Ricardo, 2017), i.e. around twice the price of fossil aviation fuel. We use reference aircraft maintenance costs per year and per flight cycle from Al Zayat et al. (2017). A decline in maintenance costs of $1 \%$ per year for historical aircraft models, and $2.5 \%$ per year increase in maintenance costs with increasing year of aircraft age (Morrell \& Dray, 2009), are assumed. Aircraft finance costs, including insurance, interest and depreciation, are modelled as in Morrell \& Dray (2009). We assume a depreciation period of 20 years, $5 \%$ aircraft residual value, and an insurance rate of $1.2 \%$ of current aircraft value.

\section{Airline policy response}

Airlines faced with regional policy costs have several options. First, if costs are greater for older aircraft (i.e. are fuel- or carbon-related, or applied in age bands), they could put younger aircraft of a given size class on policy-affected routes and move older aircraft onto routes outside the policy area. This will increase emissions outside the policy area, leading to leakage. Additionally, some airline groups purchase fleet in common, allowing a wider pool of aircraft to switch. In theory this is a minimal-cost option for airlines as aircraft are already widely switched between routes. However, there may be barriers to doing this in practice (e.g. Roy, 2007; Nero \& Black, 2000). 
We treat the extent of fleet swapping as an uncertain variable and consider two cases: one where airlines do not swap fleet, and one where airline groups can swap fleet within size classes between UK and non-UK routes if this will reduce their overall policy costs.

Second, airlines could choose to sell or lease out older aircraft in their fleet and buy or lease in newer aircraft. Capital costs act as a barrier here. Morrell \& Dray (2009) find early replacement of a 15-year old 150-seater aircraft not cost-effective even at oil prices of $\$ 140 / \mathrm{bbl}$ and carbon prices of $\$ 100 / \mathrm{tCO}_{2}$. To model this decision, we use the Net Present Value (NPV) model of Morrell \& Dray (2009), assuming a discount rate of $10 \%$ over a period of seven years.

Third, if the policy increases fuel costs at policy area airports, airlines could choose to take on enough fuel at a non-policy area airport to fly into the policy area and back out again without refuelling (tankering). Tankering is only possible if the aircraft is below maximum takeoff weight (MTOW) on first takeoff, below maximum landing weight (MLW) on first landing, and if there is sufficient fuel capacity. This limits the practice to short-haul flights. We model tankering using the model for fuel use described above. Extra fuel is treated as increased payload. This typically results in a 3$10 \%$ increase in UK arriving flight fuel where tankering occurs.

Airlines may also invest in retrofits or make operational changes to save fuel; however, as discussed in Dray et al. (2018), the overall fuel burn reductions available from these measures are relatively small; most are either cost-effective without extra policy or not cost-effective even at high carbon prices.

Finally, airlines can choose to absorb remaining costs and accept a reduced profit margin, or pass costs on to ticket price. The extent to which this occurs is uncertain (e.g. Anger \& Köhler, 2010). There is evidence that pass-through at noncongested airports is close to 100\% (Vivid Economics, 2007). For congested airports 
(operating at or approaching declared movement per hour capacity) it has been argued that optimal price levels are set by constrained supply rather than demand, leading to 0\% pass-through (e.g. Ernst and Young \& York Aviation, 2008); and that cost increases may be factored into slot prices (Faber \& Brinke, 2007). However, if per-passenger cost increases exceed airline profit margin, $0 \%$ pass-through is unlikely. We treat cost passthrough at congested airports (for the UK, London Heathrow and London Gatwick; DfT, 2017) as an uncertain variable. Values of $0 \%, 50 \%$ and $100 \%$ are considered. Most international-international traffic routing through the UK passes through Heathrow (e.g. Sabre, 2017).

\section{Passenger policy response}

We assume that passengers book trips on a whole-itinerary, round-trip basis, i.e. a passed-on increase in policy-related cost on a single segment is experienced as an increase in ticket price per round-trip itinerary. Passenger response is then captured using the price elasticity and itinerary choice models described above.

\section{Policies}

We consider three hypothetical policies with different impacts on airline costs and emissions:

- A carbon price applied to UK departing flights only, at levels between $\$ 15-300 / \mathrm{tCO}_{2}(£ 10-200 / \mathrm{tCO} 2)$. For comparison, IPCC (2018) project that global carbon prices in IPCC (2018) in 2030 would need to be \$10$200 / \mathrm{tCO}_{2}$ across $2^{\circ} \mathrm{C}$ warming scenarios, and $\$ 135-5,500 / \mathrm{tCO}_{2}$ across $1.5^{\circ} \mathrm{C}$ warming scenarios. A $\$ 300 / \mathrm{tCO}_{2}$ carbon price would more than double the effective year-2015 airline fuel price. 
- A requirement to use a given fraction of biofuel in UK departing flights, between 5 and $40 \%$. We assume a constant biofuel price and that all biofuel needed can be supplied (i.e., for 2015 this is hypothetical due to lack of commercial-scale biofuel production). Under the assumptions used here, $40 \%$ biofuel use would increase year-2015 effective fuel prices to airlines by around $40 \%$. Biofuel aviation-attributable emissions are assumed to be $30 \%$ of those of fossil-derived aviation kerosene (DfT, 2017).

- A bonus-malus1 type increase in landing charges at UK airports, for which landing costs for aircraft over 15 years old are increased by $\$ 380$ 3000 ( $£ 250-2000$ ), and landing costs for aircraft under 5 years old are decreased by the same amount. These age thresholds are chosen such that the overall policy is broadly cost-neutral for airlines with current average UK fleets (Figure 1). For comparison, UK airport landing charges can be up to around $\$ 15,000 /$ landing for large aircraft at major airports, but are closer to $\$ 1,000-2,000 /$ landing for regional jets (RDC, 2017).

For each policy, we assess outcomes across a range of values for price elasticity of demand, cost pass-through at congested airports, and airline fleet substitution level. Additional model runs to assess sensitivity to global carbon, fuel and biofuel prices and

1 A bonus-malus arrangement rewards desired behaviour (in this case, the use of newer aircraft which typically have lower emissions) and penalises undesired behaviour (the use of older aircraft). 
airline purchasing assumptions were carried out but indicated relatively small impacts on leakage outcomes. Leakage is defined as in IPCC (2007), i.e.

Leakage $=\frac{-\Delta \mathrm{CO}_{2, \text { outside policy area }}}{\Delta \mathrm{CO}_{2, \text { within } \text { policy area }}}$,

and is expressed in percentage terms.

\section{Policy assessment scope}

A single flight may involve airspace and airports belonging to multiple countries.

Emissions can be attributed to those countries in different ways. For example, emissions from all departing flights are often used (DfT, 2017). This is the same as emissions from country-level fuel uptake unless tankering occurs. Using all arriving and departing flights allows for a fuller coverage of policy impacts, but risks emission doublecounting between different countries. Using emissions associated with passengers normally resident in each country may reduce distortions due to transfer passengers, but relies on data which may not always be available (Larsson et al, 2019). In this paper we consider the first three scopes, and how leakage metrics differ between them.

\section{Model outcomes}

\section{Baseline system}

Table 1 shows baseline model outcomes in 2015, compared to observed data (CAA, 2017b; DfT, 2017). Passenger and aircraft movements are reproduced to within around $5 \%$ of observed totals on a system-wide basis and at individual airports (excepting London Stansted, which has more non-scheduled flights than modelled). Model $\mathrm{CO}_{2}$ outcomes are around $10 \%$ below observed UK fuel uptake values. This likely arises from the combination of small under-predictions in demand; performance modelling assuming ideal use conditions; and the use of a single factor for non-scheduled flights. 
Since leakage is a function of relative rather than absolute changes in $\mathrm{CO}_{2}$, this level of under-prediction should have minimal impact on leakage outcomes.

Table 2 shows the distribution of scheduled-only passengers and $\mathrm{CO}_{2}$ by itinerary type and scope. The largest component of $\mathrm{CO}_{2}$ is passengers on international direct routes. Assuming these are round-trip journeys, $50 \%$ of the $\mathrm{CO}_{2}$ emitted by these passengers is on UK departing flights, and 50\% on UK arriving flights. For example, if emissions are attributed between countries on a departing flights basis, half of the $\mathrm{CO}_{2}$ associated with a London-New York round trip would be attributed to the UK, and half to the US. If a cost increase causes demand on this route to go down, half of the associated $\mathrm{CO}_{2}$ reduction would be attributed to the $\mathrm{UK}$, and half would count as nonUK reductions - i.e., negative leakage of around $100 \%$.

Substantial amounts of $\mathrm{CO}_{2}$ are also associated with $\mathrm{UK}$ origin and destination passengers who make a further stop at a non-UK hub (for example, London to Sydney via Dubai). For a round-trip journey of this type, typically $25 \%$ of total $\mathrm{CO}_{2}$ is in $\mathrm{UK}$ departing flight scope (London-Dubai); $25 \%$ in UK arriving flight scope (DubaiLondon); and $50 \%$ is on flights neither to or from the UK (Dubai-Sydney, SydneyDubai). On a departing flights or fuel uptake scope, this means that a reduction in London-Sydney demand is associated with negative leakage of over $100 \%$. On a UK arriving and departing flights scope, demand-related leakage for these flights is still negative because the Dubai-Sydney-Dubai component remains outside UK scope.

The third-highest component is associated with international-international transfer passengers who hub via the UK. Around $50 \%$ of the round-trip $\mathrm{CO}_{2}$ from these 
passengers is on a UK departing flight scope and $50 \%$ on a UK arriving flight scope. If these passengers switch to a non-UK hub, the $\mathrm{CO}_{2}$ associated with them is attributed to non-UK countries under all scopes (around 100\% positive leakage).

The total leakage associated with passenger behaviour is a combination of these effects. To illustrate the demand and itinerary choice response, we run a test case with a high carbon price $\left(\$ 300 / \mathrm{tCO}_{2}\right)$ and $100 \%$ cost pass-through at all airports. Outcomes for low passenger price elasticity $(-0.2)$ are shown in Table 2 . The second-largest single impact on $\mathrm{CO}_{2}$ is international-international passengers changing itinerary from UK hubs to non-UK ones (positive leakage). However, there is a larger $\mathrm{CO}_{2}$ impact from passengers on UK origin and destination routes choosing not to fly. Although price sensitivity is low, the much larger number of passengers makes this impact dominant. Depending on scope, this may result in a small amount of negative leakage (arriving and departing flights scope) or a larger amount (fuel uptake or departing flights scopes). This is because of the UK arriving and non-UK emissions components of the itinerary types discussed above. As the price elasticity of demand assumed becomes more negative, negative leakage becomes more dominant. For example, leakage on a UK departing flights/fuel uptake basis in the test case shown in Table 2 is around $-60 \%$. If a price elasticity of demand of -0.8 is used, it is $-115 \%$.

\section{Response to Policy}

The range of leakage outcomes by scope, policy type and values for uncertain variables is shown in Figure 2. For fleet swap outcomes, we additionally show the impact of individual uncertain variables. Because the landing charge policy is aimed at influencing fleet composition, outcomes without fleet swapping display minimal change in emissions and are omitted from the plot. 
Several broad trends are universally applicable. First, if airlines switching fleet between UK and non-UK routes is modelled ('fleet swapping'), even a small increased policy cost makes it cost-effective to swap fleet to the extent possible, as this response carries low to no cost for airlines. The corresponding decrease in emissions on routes to and from the UK, and increase in emissions on non-UK routes, leads to positive leakage which may approach $100 \%$ at low policy stringencies, i.e. the main outcome in these cases is that the same fleet operates on different routes. Second, leakage where fleet swap is not assumed is significantly lower/more negative. This is because airlines cannot reduce costs by fleet swapping in this case, meaning that more costs are passed on to passengers, leading to demand impacts whose leakage impact is frequently negative. Third, the magnitude of leakage is smaller and less uncertain if leakage is evaluated on an all flights basis rather than in terms of departing flights or fuel uptake. This is because the round-trip demand impacts on UK direct international itineraries are wholly within scope on an all flights basis.

For a carbon price applied to UK departing flights (Figure 2, column (a)), leakage is sensitive to uncertain variables, but typically negative. This is because this policy results in substantial increases in airline costs, and hence substantial changes in ticket prices and demand. Leakage is more negative if cost pass-through is greater and/or passengers are more price-sensitive, because reductions in round-trip demand are greater. The largest component of negative leakage on a departing flights or fuel uptake basis is the decrease in demand on UK arriving flights. If leakage is evaluated on an arriving and departing flights basis, the negative leakage component is smaller and arises only from non-UK legs of UK origin and destination itineraries that hub outside the UK. In the highest carbon price case modelled $\left(\$ 300 / \mathrm{tCO}_{2}\right)$, global $\mathrm{CO}_{2}$ decreases by between 0.9 and $12.9 \mathrm{Mt}$, mainly due to long-haul reductions in demand. 
The case of mandatory use of biofuel on UK departing flights is more complex (Figure 2, column (b)). The airline cost increase from this policy at the levels investigated is lower, leading to reduced demand and itinerary choice impacts. Airlines can avoid this policy by tankering fuel where feasible and cost-effective. Figure 3 shows impacts on effective fuel price; the amount of $\mathrm{CO}_{2}$ tankered; and the geographic distribution of tankering routes at $10 \%$ and $40 \%$ biofuel requirement. Tankering potential saturates at around $20 \%$ biofuel under the fuel price assumptions used here. The net impact of tankering strongly depends on policy evaluation scope. On a fuel uptake basis, it moves up to $2 \mathrm{MtCO}_{2}$ from $\mathrm{UK}$ airports to non-UK airports, leading to positive leakage. On a departing flights scope, there is a small positive leakage component from increases in arriving flight emissions $\left(<0.2 \mathrm{MtCO}_{2}\right)$ and reduced policy effectiveness. On an arriving and departing flights scope, the only impact is to decrease policy effectiveness. Net leakage from the biofuel policy combines tankering, fleet swap (where included), demand and itinerary choice impacts. Of these, the tankering and fleet swap impacts are largest, leading to typically $0-50 \%$ positive leakage. In the highest biofuel fraction case modelled (40\%), global $\mathrm{CO}_{2}$ decreases by between 8.3 and $9.6 \mathrm{Mt}$, mainly due to reductions in fuel lifecycle $\mathrm{CO}_{2}$ from biofuel use, with a secondary longhaul demand impact.

The environmental landing charge policy is approximately cost-neutral with current fleet age distributions (Figure 1). As landing charges increase for older aircraft and decrease for younger aircraft, airlines can reduce costs (i.e. make a net saving over the baseline) by swapping fleet and/or buying new aircraft. This policy affects shorthaul flights by small aircraft the most. A regional jet on a domestic route might land ten times a day at UK airports, compared to one or two landings per day by a long-haul 
twin-aisle aircraft (e.g. FlightGlobal, 2017). The main airline response to this policy is to swap fleet where this reduces costs, and in some cases to purchase new short-haul aircraft and sell older ones to non-UK operators. If an overall cost saving is possible, ticket prices may decrease. This in turn leads to a demand rebound effect primarily on UK short-haul routes. This increase in demand will lead to a smaller-than-expected decrease in policy area $\mathrm{CO}_{2}$. For return trips, the increase in demand leads an increase in arriving flight $\mathrm{CO}_{2}$, i.e. positive leakage on a fuel uptake or departing flights policy scope. With more price-sensitive passengers and/or higher landing charge savings, the demand rebound wipes out much of the $\mathrm{UK}$-attributable $\mathrm{CO}_{2}$ reductions, leading to positive leakage in excess of $100 \%$. As shown in Figure 2, column (c), the overall impact with fleet swapping is positive leakage of $50-150 \%$. In the highest landing charge case modelled ( $\pm \$ 3000 /$ landing), overall global $\mathrm{CO}_{2}$ changes by between -0.3 and +0.6 Mt. If fleet swap is not assumed, changes in demand and emissions are minimal.

\section{Discussion and conclusions}

This study is the first to analyse, on an in-depth network basis, the carbon leakage impacts of aviation policy. We find that carbon leakage due to aviation may be substantial, ranging between around $+150 \%$ and $-150 \%$ for the selection of UK-specific policies investigated, and that it is strongly impacted by the exact policy type assumed, the price sensitivity of passengers, the amount of cost pass-through at congested airports, and whether airlines and airline groups can freely swap fleet between different routes. This is a larger range than has been projected for other sectors. It reflects several factors. First, passenger demand is usually on a round-trip basis and longer trips can involve multiple non-UK flight legs, but emissions are typically attributed to countries based on a less complex scope (for example, departing flights). This means that any 
change in UK passenger demand can be accompanied by substantial changes in non-UK attributable emissions (for example, on UK arriving flights), leading to higher (usually negative) leakage, that is, lower emissions overall. Second, low-cost options are available to airlines to shift the location of emissions outside the policy area, for example tankering fuel and switching aircraft between routes. For policies that target airline rather than passenger response, these factors can lead to positive leakage, that is, higher emissions overall. Third, flights to and from the UK dominate over flights within the UK, leading to greater potential for both positive and negative leakage.

These results will broadly apply to policies in other individual countries with more international than domestic flights. This is because most of the leakage mechanisms investigated apply to flights into and out of the policy area and/or airlines which operate both inside and outside the policy area. Similarly, they are likely to apply to action by individual airports or groups of airports. For larger countries, where domestic flights make up a greater proportion of overall flights, we would expect the magnitude of leakage to reduce.

It is possible to attribute aviation emissions to a country or region in several different ways. The exact attribution method also makes a substantial difference to the leakage metric. Although this is only an accounting difference and does not have an impact on the net global change in $\mathrm{CO}_{2}$, these differences can be important if they affect whether a policy is judged to be successful or not.

Of the policies investigated, carbon pricing is associated with the best leakage outcome. Under many combinations of uncertain variables, leakage from carbon pricing is negative, that is, emission reduction extends even outside the policy arena. This is because the dominant source of emissions reduction is demand reduction, including for multi-segment round-trip itineraries with flight segments both within and outside the 
policy area. The highest carbon prices modelled $\left(\$ 300 / \mathrm{tCO}_{2}\right)$ would more than double year-2015 airline fuel costs. This level of change is comparable to recent fluctuations in aviation fuel prices and to IPCC (2018) estimates of year-2030 carbon prices in $2^{\circ} \mathrm{C}$ warming scenarios, but absolute values still far exceed historical EU ETS carbon prices, which are typically below $\$ 30 / \mathrm{tCO}_{2}$ (European Climate Exchange, 2018). Given the extent of aviation industry resistance to including aviation in the EU ETS, carbon prices at the higher end of the range modelled would likely face significant challenges in implementation and values within the mid or lower end of the range explored are more likely. However, even at lower values of carbon price negative leakage frequently occurs.

We also explore a hypothetical biofuel adoption policy, in which a mandatory biofuel requirement increases the price of refuelling at UK airports. In this case, the dominant source of emissions reduction is fuel lifecycle emissions reduction from biofuel use, and leakage is typically positive and up to $40 \%$. Leakage arises from a combination of positive and negative sources, including fuel tankering, passenger demand response, and airline fleet response. The overall global change in $\mathrm{CO}_{2}$ at the stringency levels investigated is of a similar order of magnitude to the carbon price policy. A $40 \%$ biofuel share in aviation (the upper end of the range modelled) is within the range of longer-term scenarios projected in the literature (e.g. Sgouridis et al. 2011). Several countries, including the UK, either have year-2050 targets for aviation biofuel use of around this level or have commissioned research exploring such targets (ICAO, 2017; Ricardo, 2017). However, the biomass needed may have greater $\mathrm{CO}_{2}$ reduction potential if used in other sectors in combination with carbon capture and storage (CCC, 2019). This suggests that the lower end of the range modelled may be more realistic; however, leakage values are similar across the range of biofuel shares modelled. 
The worst leakage outcomes are associated with a bonus-malus type change in landing charges at airports in the policy area. Here the dominant leakage mechanisms are associated with airline fleet response and demand rebound. In combination, these impacts can lead to positive leakage above $100 \%$, i.e. a net global increase in aviation $\mathrm{CO}_{2}$. The maximum landing charge changes modelled are well within the range of variation in landing charges between airports for large aircraft (RDC, 2016) but may result in a doubling or more in landing costs for small aircraft. Implementing such a policy would likely require smaller landing charge changes for smaller aircraft, but would still result in positive leakage.

Any country-level aviation policy will also interact with wider aviation policy, in particular any future developments of the EU ETS and/or CORSIA, and this may in turn have impacts on leakage. The policies examined here are assumed additional to ETS/CORSIA carbon prices and outcomes are relatively insensitive to assumptions about those prices. However, by reducing the amount that airlines pay to other sectors via the ETS price and/or CORSIA offsetting, there is potential for smaller emissions reductions in those sectors. As argued by Larsson et al. (2019), national-level policy instruments remain valuable in this context, for several reasons: they provide withinsector mitigation of both $\mathrm{CO}_{2}$ and non- $\mathrm{CO}_{2}$ impacts; many offset schemes have questionable additionality; and the EU ETS has recently been adjusted so that absolute aviation $\mathrm{CO}_{2}$ reductions cannot lead to increases in other sectors (European Council, 2018). However, the question of the amount by which these effects might reduce policy effectiveness is worth revisiting when the final form of the interaction between the EU ETS and CORSIA has been decided. Similarly, additional leakage to that modelled here may arise from the impact of reductions in fossil fuel use on fuel prices (both within aviation and in other sectors), and the interaction of this with other emissions mitigation 
schemes such as the EU ETS (Burniaux \& Oliveira Martins, 2000; Rosendahl \& Strand, 2011).

This study suggests that limiting carbon leakage from aviation policy requires policies which target passenger rather than airline response; which apply to a larger geographic area; and which address specific mechanisms for policy avoidance where appropriate (for example, fuel tankering). More generally, aviation should be treated as a sector at high risk of leakage for policies applied by individual countries.

\section{References}

Al Zayat, K., Dray, L. \& Schäfer, A. (2017). A first-order analysis of direct operating costs of battery-electric aircraft. 21 st ATRS World Conference, Antwerp, July 582017.

Anger, A. \& Köhler, J. (2010). Including aviation emissions in the EU ETS: much ado about nothing? Transport Policy, 17(1), 38-46.

Brons, M., Pels, E., Nijkamp, P. \& Rietvald, P. (2002). Price elasticities of demand for passenger air travel: a meta-analysis. Journal of Air Transport Management, $8(3), 165-175$.

Burniaux, J. \& Oliveira Martins, J. (2000). Carbon Leakages: A General Equilibrium View. OECD Economics Department Working Papers, No. 242, OECD Publishing, Paris.

CAA, (2017). UK Airport Data. https://www.caa.co.uk/Data-and-analysis/UK-aviationmarket/Airports/Datasets/UK-airport-data/

CCC, 2019. Net Zero: The UK's Contribution to Stopping Global Warming. https://www.theccc.org.uk/wp-content/uploads/2019/05/Net-Zero-The-UKscontribution-to-stopping-global-warming.pdf

CE Delft, 2005. Inclusion of aviation under the European emissions trading scheme (ETS): design and impacts. https://www.cedelft.eu/en/publications/334/givingwings-to-emission-trading, Delft, 2005.

Di Maria, C. \& van der Werf, E. (2008). Carbon leakage revisited: unilateral climate policy with directed technical change. Environ. Resource Econ., 39, 55-74. 
Intergovernmental Panel on Climate Change (2007). IPCC Climate Change 2007:

Mitigation. Cambridge: Cambridge University Press.

Dray L., Krammer P., Doyme K., Wang B., Al Zayat K, O’Sullivan A. \& Schäfer A. (2019). AIM2015: Validation and Initial Results from an Open-Source Aviation Systems Model. Transport Policy, 79, 93-102.

Dray, L., Schäfer, A. \& Al Zayat, K., 2018. The global potential for $\mathrm{CO}_{2}$ emissions reduction from jet engine passenger aircraft. Transportation research Record, in press.

Ernst \& Young and York Aviation (2008). Inclusion of aviation in the ETS: Cases for Carbon Leakage. https://www.verifavia.com/bases/ressource_pdf/112/AN-EYFULL-TEXT-OCT08.pdf

European Climate Exchange, 2018. Carbon prices on the European Climate Exchange. http://www.ecx.eu/

European Council, 2018. Reform of the EU emissions trading system - Council endorses deal with European Parliament. Brussels, 2018.

Faber, J. \& Brinke, L., 2011. The inclusion of aviation in the EU Emissions Trading System. ICTSD Issue Paper No. 5. ICTSD, Geneva.

FlightGlobal, 2016. Ascend Online Fleet Database. http://www.ascendworldwide.com/what-we-do/ascend-data/aircraft-airlinedata/ascend-online-fleets.html.

Givoni, M, \& Rietveld, P. (2009). Airline's choice of aircraft size - Explanations and implications. Transportation Research Part A, 43(5), 500-510.

ICAO (2014). ICAO Annual Report, 2014: Appendix 1. https://www.icao.int/annualreport-2014/Documents/Appendix_1_en.pdf.

IATA (2007). Estimating air travel demand elasticities. https://www.iata.org/whatwedo/Documents/economics/Intervistas_Elasticity_St udy_2007.pdf

IATA (2017). IATA Sustainable Aviation Fuel Roadmap. Retrieved from https://www.iata.org/whatwedo/environment/Documents/safr-1-2015.pdf

IPCC (2018). Global warming of $1.5^{\circ} \mathrm{C}$. Retrieved from http://www.ipcc.ch/report/sr15/.

Kuik, O. \& Hofkes, M. (2010). Border adjustment for European Emissions Trading: competitiveness and carbon leakage. Energy Policy, 38(4), 1741-1748. 
Larsson, J., Elofsson, A., Sterner, T, \& Åkerman, J., (2019). International and national climate policies for aviation: a review. Climate Policy, 19(6), 787-799.

Lee, J., Lukatchko „S., Waitz, I. \& Schäfer, A. (2001). Historical and Future Trends in Aircraft Performance, Cost and Emissions. Annual Review of Energy and the Environment, 17, 537-573.

Lissys (2017). The PIANO X Aircraft Performance Model. www.piano.aero.

Martinez Romera, B. (2016). The Paris Agreement and the Regulation of International Bunker Fuels. Review of European Community and International Environmental Law, 25(2), 215-227.

Morrell, P., and Dray, L. (2009). Environmental aspects of fleet turnover, retirement and life cycle. Final report for the Omega consortium.

http://bullfinch.arct.cam.ac.uk/documents/FleetTurnover_CranfieldCambridge.p df .

Nero, G., \& Black, J. A. (2000). A critical examination of an airport noise mitigation scheme and an aircraft noise charge. Transportation Research Part D, 5(6), 433461

Oum, T., Waters, W. \& Yong, J. (1992). Concepts of price elasticities of transport demand and recent empirical estimates. Journal of Transport Economics and Policy, 26(2), 139-154.

Porter, M., \& van der Linde, C. (1995). Towards a New Conception of the Environment-Competitiveness Relationship. Journal of Economic Perspectives, 9(4), 97-118.

RDC (2017). RDC Aviation airport and enroute charges databases.

http://www.rdcaviation.com/.

Reinaud, J. (2008). Issues behind competitiveness and carbon leakage. OECD/IEA, Paris

Ricardo (2017). Carbon Abatement in UK Aviation. Report for Department for Transport.

https://assets.publishing.service.gov.uk/government/uploads/system/uploads/atta chment_data/file/653776/carbon-abatement-in-uk-aviation.pdf.

Rosendahl, R. \& Strand, J., 2011. Carbon Leakage from the Clean Development Mechanism. The Energy Journal, 34(4), 27-50. 
Roy, R. (2007). A cost-effectiveness analysis of local air quality charges at Zurich and Stockholm airports. In ICAO Environmental Report 2007, ICAO, Montreal, 2007.

Sgouridis, S., Bonnefoy, P. \& Hansman, R. J., 2011. Air transportation in a carbon constrained world: long-term dynamics of policies and strategies for mitigating the carbon footprint of commercial aviation. Transportation Research Part A, 45, 1077-1091.

Sabre, 2017. Market Intelligence database.

https://www.sabreairlinesolutions.com/home/software_solutions/product/market _competitive_intelligence/

Vivid Economics, 2007. A study to estimate ticket price changes for aviation in the EU ETS. http://www.vivideconomics.com/wpcontent/uploads/2015/03/Vivid_Econ_Aviation_Tickets.pdf 
Table 1. Baseline system metrics, model and observed data, 2015.

\begin{tabular}{|l|l|l|l|l|l|}
\hline Metric & Source & UK & UK departing & UK arriving & Non-UK \\
\hline \multirow{2}{*}{ Yearly } & Model & 635,000 & 737,000 & 734,000 & $1,601,000$ \\
\cline { 2 - 7 } movements & CAA, & 600,000 & 755,000 & - & - \\
\hline \multirow{2}{*}{ Passengers, } & Model & 43.7 & international & international & \\
\cline { 2 - 7 } mppa & CAA, & 41.2 & 99.6 & 100.3 & 138.8 \\
\cline { 2 - 7 } & 2017 & & 105.1 & - & - \\
\hline \multirow{2}{*}{ CO2, Mt } & Model & 1.83 & 29.6 & 29.1 & \\
\cline { 2 - 7 } & DfT, & 1.52 & 32.9 & & \\
\hline
\end{tabular}


Table 2. Scheduled passengers and $\mathrm{CO}_{2}$ by itinerary type and scope, baseline and change from baseline for a $\$ 300 / \mathrm{tCO}_{2}$ test case with -0.2 demand elasticity and $100 \%$ cost pass-through.

\begin{tabular}{|c|c|c|c|c|c|c|}
\hline Itinerary type & $\begin{array}{l}\text { Total } \\
\text { Passengers, } \\
\text { mppa }\end{array}$ & $\begin{array}{l}\mathrm{CO}_{2} \text { in } \\
\mathrm{UK} \\
\text { departing } \\
\text { flight } \\
\text { scope, Mt }\end{array}$ & $\begin{array}{l}\mathrm{CO}_{2} \\
\text { outside } \\
\text { UK } \\
\text { departing } \\
\text { flight } \\
\text { scope, Mt }\end{array}$ & $\begin{array}{l}\text { Test case } \\
\text { change in } \\
\text { passengers, } \\
\text { mppa }\end{array}$ & $\begin{array}{l}\text { Test case } \\
\text { change in } \\
\mathrm{CO}_{2} \text { in } \\
\mathrm{UK} \\
\text { departing } \\
\text { flight } \\
\text { scope, } \mathrm{Mt}\end{array}$ & $\begin{array}{l}\text { Test case } \\
\text { change in } \\
\mathrm{CO}_{2} \\
\text { outside } \\
\text { UK } \\
\text { departing } \\
\text { flight } \\
\text { scope, } \mathrm{Mt}\end{array}$ \\
\hline UK domestic & 18.8 & 1.6 & 0.0 & -0.60 & -0.06 & 0.0 \\
\hline $\begin{array}{l}\text { UK } \\
\text { international } \\
\text { departing } \\
\text { direct }\end{array}$ & 68.9 & 15.2 & 0.0 & -1.4 & -0.44 & 0.0 \\
\hline $\begin{array}{l}\text { UK } \\
\text { international } \\
\text { arriving direct }\end{array}$ & 68.5 & 0 & 15.2 & -1.5 & 0.0 & -0.45 \\
\hline $\begin{array}{l}\text { UK departing } \\
\text { via UK hub }\end{array}$ & 0.78 & 0.53 & 0.03 & -0.07 & -0.04 & -0.002 \\
\hline $\begin{array}{l}\text { UK arriving } \\
\text { via UK hub }\end{array}$ & 0.79 & 0.06 & 0.5 & -0.07 & -0.005 & -0.04 \\
\hline $\begin{array}{l}\text { UK departing } \\
\text { via non-UK } \\
\text { hub }\end{array}$ & 9.8 & 5.0 & 4.4 & -0.10 & -0.15 & 0.01 \\
\hline $\begin{array}{l}\text { UK arriving } \\
\text { via non-UK } \\
\text { hub }\end{array}$ & 10.6 & 0.005 & 10.1 & -0.11 & 0.0 & -0.15 \\
\hline $\begin{array}{l}\text { International- } \\
\text { international } \\
\text { transfer via } \\
\text { UK }\end{array}$ & 8.7 & 4.7 & 4.9 & -0.64 & -0.30 & -0.32 \\
\hline $\begin{array}{l}\text { International- } \\
\text { International } \\
\text { transfer via } \\
\text { non-UK } \\
\end{array}$ & 37.4 & 0.0 & 38.7 & 0.31 & 0.0 & 0.28 \\
\hline $\begin{array}{l}\text { International- } \\
\text { international } \\
\text { direct }\end{array}$ & 25.2 & 0.0 & 18.9 & 0.12 & 0.0 & 0.08 \\
\hline
\end{tabular}




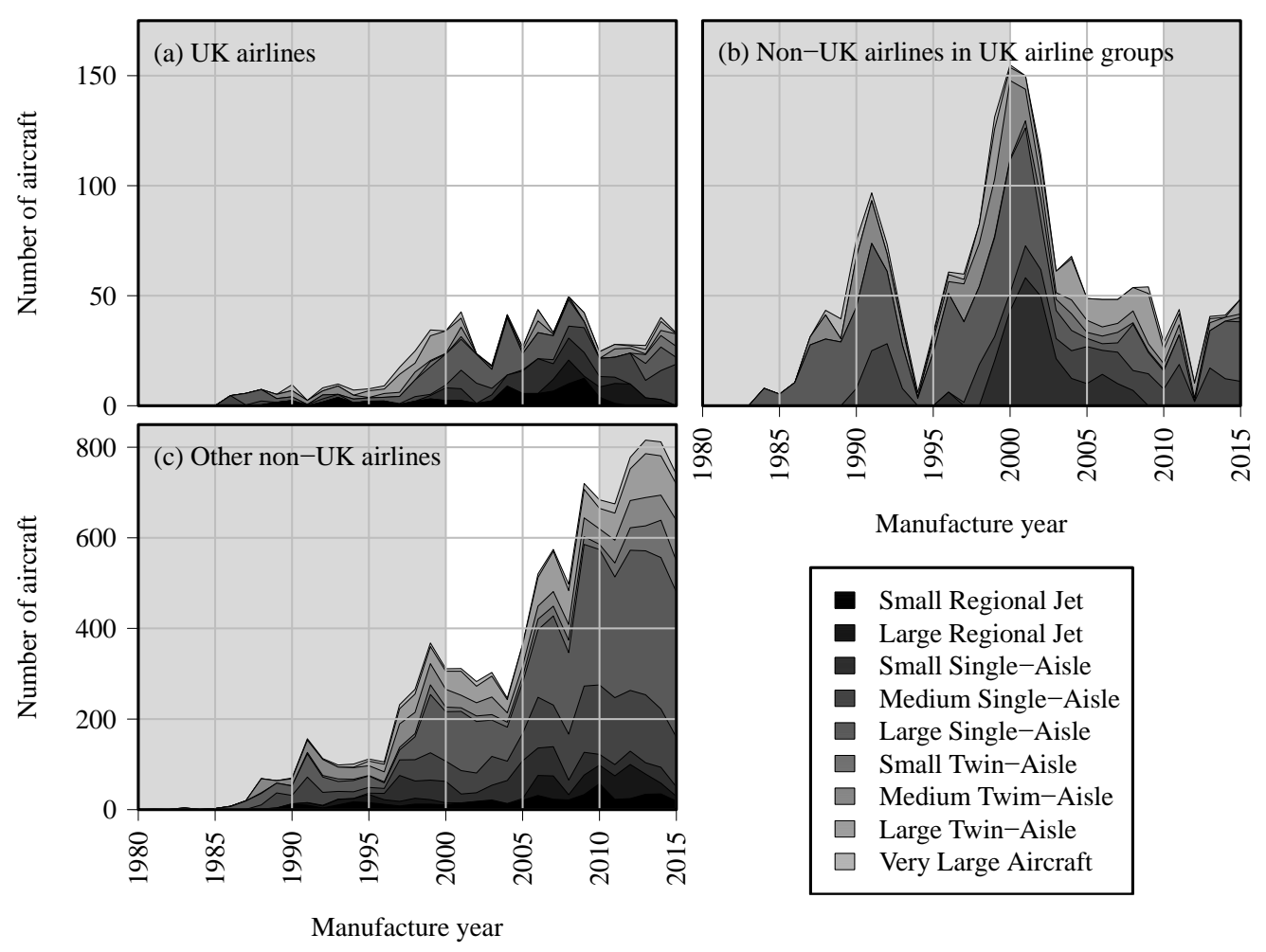

Figure 1. Year-2015 aircraft age distributions by size class and airline type: (a) UK airlines; (b) Non-UK airlines which are in or are projected to join airline groups containing UK airlines; (c) Other non-UK airlines. 

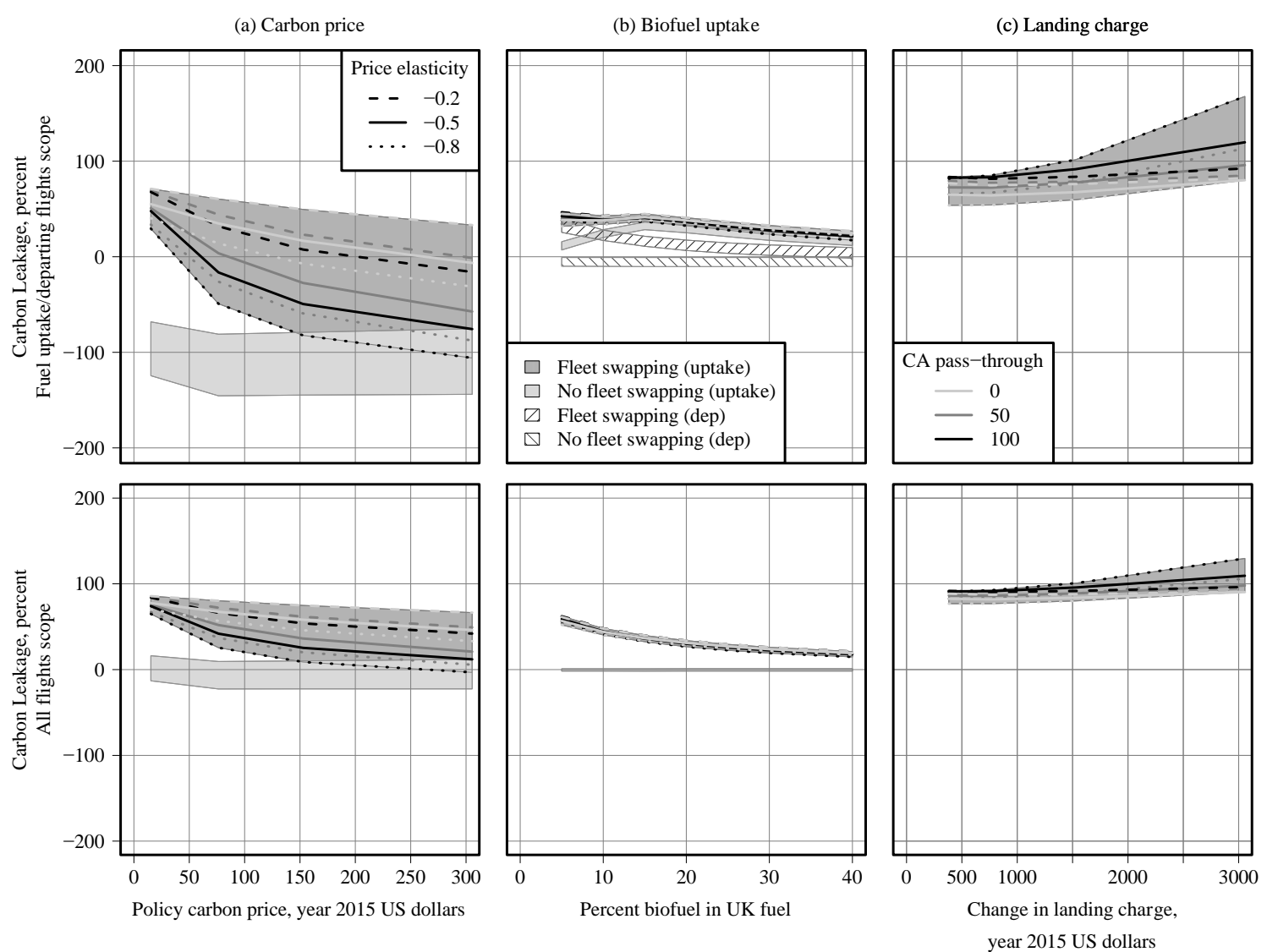

Figure 2. Carbon leakage by scope, values for uncertain variables and policy type. (a) carbon price on departing flights; (b) mandatory biofuel uptake on departing flights; (c) bonus-malus type environmental landing charges. For the non-fleet swapping case only the range over all uncertain variables is shown. 

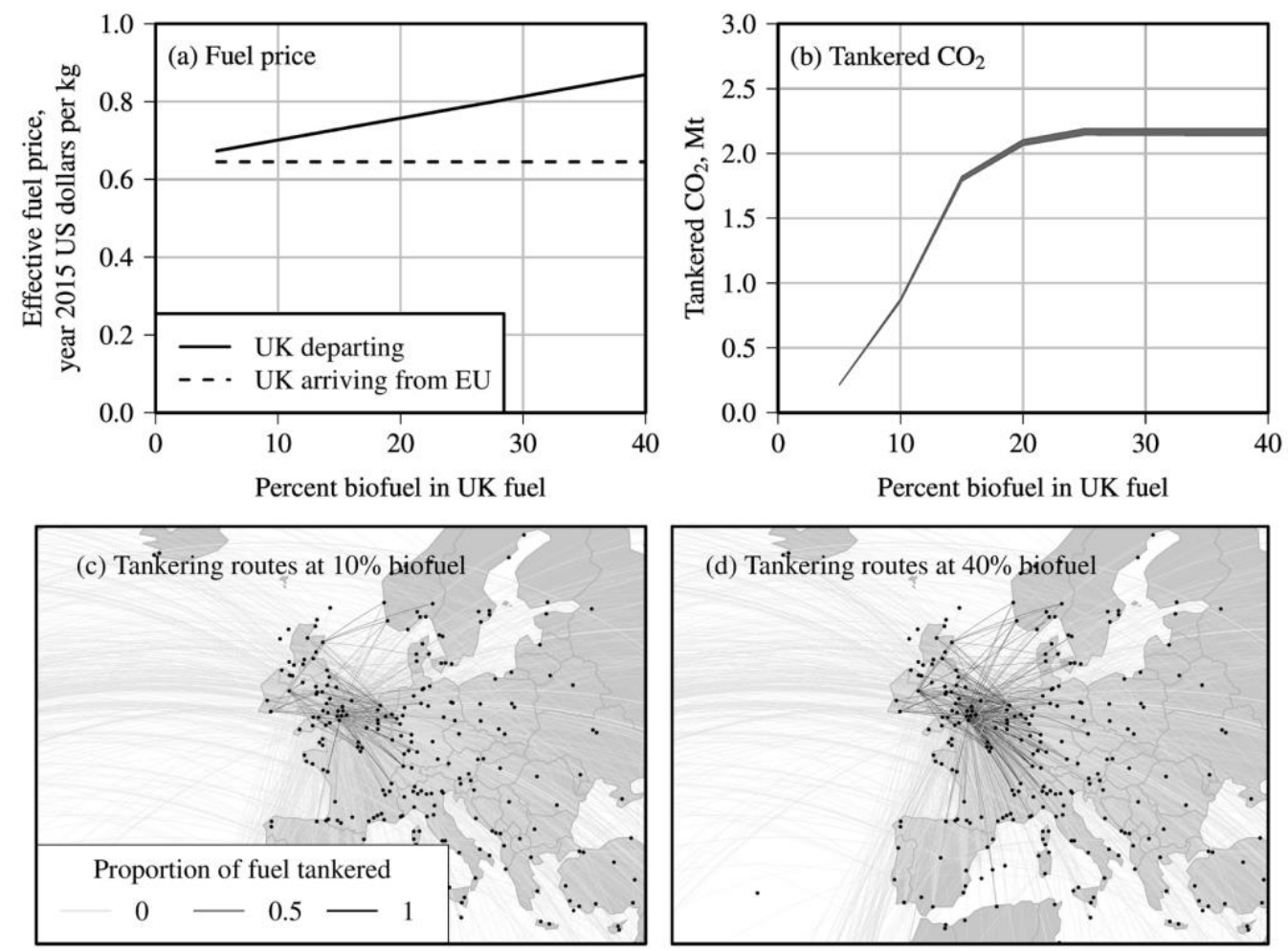

(d) Tankering routes at $40 \%$ biofuel

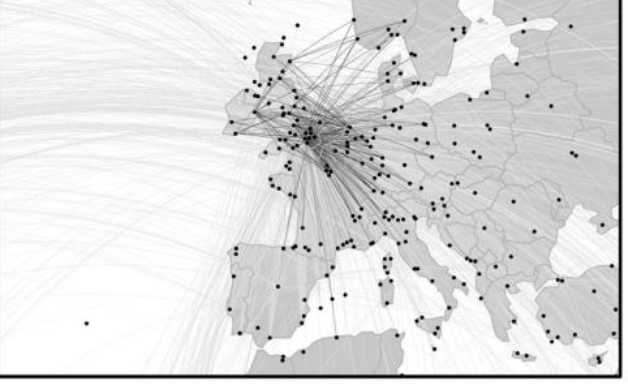

Figure 3. Tankering impact of mandatory biofuel uptake: (a) difference in effective fuel price between policy and non-policy routes; (b) the corresponding amount of tankered $\mathrm{CO}_{2} ;$ (c), (d) geographic distribution of tankering routes at $10 \%$ and $40 \%$ biofuel requirement. 